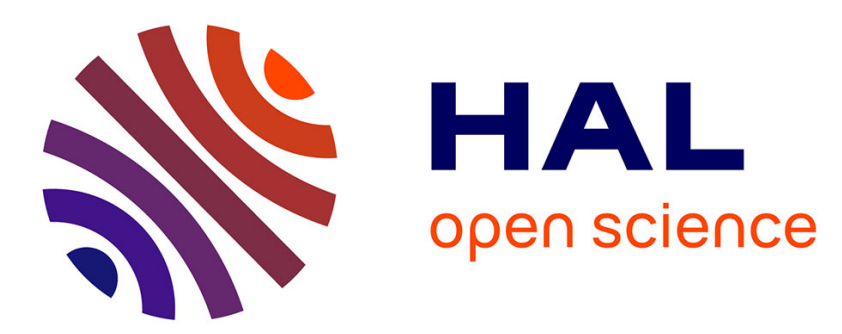

\title{
Micromechanical Modeling of Ductile Fracture Initiation to Predict Fracture Toughness of Reactor Pressure Vessel Steels
}

\author{
R. Chaouadi, P. de Meester, M. Scibetta
}

\section{- To cite this version:}

R. Chaouadi, P. de Meester, M. Scibetta. Micromechanical Modeling of Ductile Fracture Initiation to Predict Fracture Toughness of Reactor Pressure Vessel Steels. Journal de Physique IV Proceedings, 1996, 06 (C6), pp.C6-53-C6-64. 10.1051/jp4:1996606 . jpa-00254434

HAL Id: jpa-00254434

https://hal.science/jpa-00254434

Submitted on 1 Jan 1996

HAL is a multi-disciplinary open access archive for the deposit and dissemination of scientific research documents, whether they are published or not. The documents may come from teaching and research institutions in France or abroad, or from public or private research centers.
L'archive ouverte pluridisciplinaire HAL, est destinée au dépôt et à la diffusion de documents scientifiques de niveau recherche, publiés ou non, émanant des établissements d'enseignement et de recherche français ou étrangers, des laboratoires publics ou privés. 


\title{
Micromechanical Modeling of Ductile Fracture Initiation to Predict Fracture Toughness of Reactor Pressure Vessel Steels
}

\author{
R. Chaouadi, P. De Meester* and M. Scibetta \\ SCK-CEN, Boeretang 200, $2400 \mathrm{Mol}$, Belgium \\ * KUL-MTM, de Croylaan 2, 3001 Heverlee, Belgium
}

\begin{abstract}
Two micromechanical models of ductile fracture are investigated and have been applied to two reactor pressure vessel steels, $18 \mathrm{MND} 5$ and A508 Cl.3: the Beremin model, based on the Rice et Tracey void growth model, and the damage work model that combines the plastic strain work to the work spent in void growth.

Due to the local nature of these models, finite element analysis needs to be performed to derive stress and strain history in order to obtain the damage kinetics of the material and geometry under consideration.

Tensile tests were performed on various geometries (notched and precracked tensile) and sizes. All specimens are in large scale yielding condition. It is found that while the critical void growth ratio decreases with the triaxiality ratio, the critical damage work is not affected. Geometry, size and orientation effects are also investigated. These effects are well described by these micromechanical models. Similar concepts are applied to sharp notch and crack tip situations. An additional parameter, the so-called characteristic distance, characterizing the process zone size, is introduced. The fracture toughness, derived from the notched bars, is within experimental uncertainties in reasonable agreement with the results obtained for cracked geometries.
\end{abstract}

\section{INTRODUCTION}

The basic micromechanisms in the ductile fracture process involve the nucleation, growth and coalescence of voids. Experimental evidence found by fractographic examination of the fracture surfaces indicates that ductile fracture is characterized by dimples. Furthermore, interrupted mechanical tests prior to fracture have shown cavity formation around second phase particles, followed by cavity growth until final coalescence. A ductile fracture model must incorporate these observations of damage development.

To completely model the ductile fracture process, the three basic micromechanistic phases should be taken into account. However, the complexity of the phenomena involved in these phases, in addition to the complex structure of the materials, does not allow a complete mathematical description of the ductile fracture process. For many materials, however, and in particular for reactor pressure vessel steels, the void growth phase dominates the damage process: nucleation can be neglected. In other words, void nucleation can be assumed to occur as soon as plastic deformation begins. Coalescence is a punctual event that can be associated with the end of the growth phase. In a flat strain-stress distribution, the coalescence occurs over a large distance and can simply be associated with the end phase of the growth process. In crack tip situations, however, an additional parameter related to the distance over which coalescence takes place enters into play.

The fundamental idea adopted here is that the same local conditions (i.e. at a scale representative of the microstructure) are required to initiate a crack in an elementary volume, whatever the loading situation. In other words, an elementary volume located in the centre of a tensile specimen or at the crack tip of a precracked specimen or in a real structure must experience the same local damage conditions to initiate a crack. 


\section{MICROMECHANICAL MODELING OF DUCTILE CRACK INITIATION}

Two models are investigated here. First, Rice and Tracey [1] suggested a theoretical void growth model which describes the variation of shape and form of a spherical cavity contained in a material under a remote strain field. This model puts emphasis on the influence of stress triaxiality (controlled by the hydrostatic tensile stress) and equivalent plastic strain. On the other hand, the damage work model incorporates into the plastic strain work the non-conservation of the local volume.

\subsection{Rice and Tracey void growth model}

To model the kinetics of void enlargement in a plastic deforming material, Rice and Tracey [1] suggested a theoretical void growth model based on a spherical cavity contained in a rigid, incompressible non-hardening material subjected to a uniform remote strain field. Considering the incompressibility property of plastic deformation and the spherical symmetry, assuming large stress triaxialities and neglecting the contribution of void shape change, Rice and Tracey [1] express the void expansion as:

$$
\frac{d R}{R}=\alpha \exp \left(\frac{3}{2} \xi\right) d \varepsilon_{p}
$$

Here $\alpha$ is a constant and $\xi$ is the triaxiality ratio: $\xi=\sigma_{h} / \sigma_{0}$, where $\sigma_{0}$ is the yield stress and $\sigma_{h}$ is the hydrostatic stress.

To account for material hardening, Beremin [2] proposed a simple modification of this equation; he suggested to replace the yield stress by the actual flow stress, i.e. the equivalent von Mises stress $\sigma_{e}$, leading to $\xi=\sigma_{h} / \sigma_{e}$.

Experimental data confirm the general validity of this model [2-7]. However, Marini.et al. [6] have shown that the factor $\alpha$, equal to 0.283 in the original Rice and Tracey model, should be increased. Their experiments investigated the influence of the volume fraction of particles on the void size. They concluded that the factor $\alpha$ should be taken as a material dependent parameter related to the volume fraction of inclusions: the larger the volume fraction, the higher $\alpha$. For a RPV steel, A508, they suggested a value close to 0.5 . Recently, Huang [8] re-evaluated the theoretical derivation of this constant and found a value of 0.427 , which fairly agrees with Marini's suggestion. In practice, however, this turns out to be not as critical: indeed, by varying the stress triaxiality, the factor $\alpha$ can be adjusted to fit the experimental data obtained with different triaxialities.

\subsection{Damage work model}

Examination of the Rice and Tracey model allows to identify two important aspects of the ductile fracture. First, the factor $\alpha$ is a material parameter characteristic of the volume fraction of the second phase particles [10]. Second, at a local microstructurally significant scale, void growth induces volume changes that cannot be neglected. In particular, the plastic strain work assuming volume conservation results in nil hydrostatic strain. The hydrostatic stress does not contribute to the material yielding.

The basic idea here is to incorporate this hydrostatic component into the expression of the plastic strain work, leading to the so-called damage work. A similar description is given by Melander [9] and Poech and Fischmeister [10].

Consequently, in an elementary volume of material containing a void (formed around an inclusion) under a remote strain field, the total energy dissipated in the cell can be subdivided into two contributions: a pure plastic deformation energy $W_{p}$ (assuming incompressibility) and a cavitation energy $W_{g}$. The cavitation energy represents the contribution of the hydrostatic stress and the resulting hydrostatic deformation into the void expansion process. The total energy, called the damage work and denoted $W_{d}$, represents the plastic strain work 
corrected for local volume change. Noting that the hydrostatic strain may be evaluated using the relation of Rice and Tracey for void expansion, the damage work $W_{d}$ can be written as [11]:

$$
W_{d}=\int_{0}^{\varepsilon}\left[1+3 \alpha \xi \exp \left(\frac{3}{2} \xi\right)\right] \sigma_{e} d \varepsilon_{p}
$$

In this formulation, the contribution of elastic strain energy is neglected.

While the void growth model does not explicitly account for the flow properties, the damage work model incorporates directly the flow properties of the material, in particular, the strain hardening of the material. The factor $\alpha$ is, as in the void growth model, a material constant characterizing the inhomogeneities present in the matrix (inclusions, precipitates, carbides).

\subsection{Determination of critical damage at crack initiation}

For both models the damage expression should be integrated over the loading path. The integration bounds correspond to the strains associated to the nucleation and coalescence phases. Thus, neglecting the nucleation strain, the lower integration bound is simply zero, which means that void growth starts at the onset of plastic deformation. As void coalescence can be identified with the end of the growth phase, the upper bound will correspond to the strain associated with a critical size of the void. The critical damage, defined as the critical value of the parameter corresponding to crack initiation, for both models will, respectively, be given by:

$$
\begin{aligned}
& \left(\frac{R}{R_{0}}\right)_{c}=\exp \left[\int_{0}^{\varepsilon_{c}} \alpha \exp \left(\frac{3}{2} \xi\right) d \varepsilon_{p}\right] \\
& W_{d c}=\int_{0}^{\varepsilon_{c}}\left(1+3 \alpha \xi \exp \left(\frac{3}{2} \xi\right)\right) \sigma_{e} d \varepsilon_{p}
\end{aligned}
$$

where $\left(\boldsymbol{R} / \boldsymbol{R}_{0}\right)_{\mathrm{c}}$ is the critical rate of void growth corresponding to crack initiation, $W_{d c}$ is the critical damage work at fracture initiation and $\varepsilon_{c}$ is the local plastic strain at fracture initiation.

Thus, in a structure, a damage function can be evaluated if the local loading history (local strains and stresses) is known. The critical value of this damage function for which ductile crack initiation occurs, is equal to the value obtained from a laboratory specimen.

The application of such models requires experimental data to define the upper bound of the integral (strain corresponding to crack initiation) and knowledge of the local strain-stress conditions (in particular, the stress triaxiality). Moreover, the flow properties of the material under consideration should be known. Thus, besides experimental data, finite element calculations are required to implement such models.

\section{EXPERIMENTAL}

Two low alloyed ferritic steels, representative of reactor pressure vessels were selected for the present work: 18MND5 and A508 Cl.3 plates. The 18MND5 steel is tested in two tensile directions: rolling (or longitudinal) and short-transverse direction ( $\mathrm{L}$ and $\mathrm{S}$ respectively) while the A508 Cl.3 is tested in the transverse direction (T). The chemical composition and tensile properties are given in Tables 1 and 2.

\begin{tabular}{|c|c|c|c|c|c|c|c|c|c|}
\hline material & $\mathrm{C}$ & $\mathrm{Si}$ & $\mathrm{Mn}$ & $\mathrm{P}$ & $\mathrm{S}$ & $\mathrm{Cu}$ & $\mathrm{Cr}$ & $\mathrm{Mo}$ & $\mathrm{Ni}$ \\
\hline A508 Cl.3 & 0.20 & 0.28 & 1.43 & 0.008 & 0.008 & 0.055 & - & 0.53 & 0.75 \\
\hline $18 \mathrm{MND} 5$ & 0.18 & 0.26 & 1.55 & 0.007 & 0.002 & 0.14 & 0.18 & 0.50 & 0.65 \\
\hline
\end{tabular}

Table 1. Chemical composition 


\begin{tabular}{|c|c|c|c|c|c|c|}
\hline material & orientation & $\begin{array}{c}\text { yield } \\
\text { stress } \\
(\mathrm{MPa})\end{array}$ & $\begin{array}{c}\text { tensile } \\
\text { strength } \\
(\mathrm{MPa})\end{array}$ & $\begin{array}{c}\text { uniform } \\
\text { elongation } \\
(\%)\end{array}$ & $\begin{array}{c}\text { total } \\
\text { elongation } \\
(\%)\end{array}$ & $\begin{array}{c}\text { reduction } \\
\text { of area } \\
(\%)\end{array}$ \\
\hline A508 Cl.3 & $\mathrm{T}$ & 451 & 599 & 12 & 24 & 71 \\
\hline 18MND5 & $\mathrm{S}$ & 505 & 645 & 12 & 23 & 68 \\
\cline { 2 - 7 } & $\mathrm{L}$ & 518 & 661 & 12 & 24 & 76 \\
\hline
\end{tabular}

Table 2. Mechanical properties at ambient temperature

The tensile tests were carried out on axisymmetrically-notched round tensile specimens. This geometry has the advantage to be easy to machine, easy to test and does not require complex and expensive 3D-finite element simulation for analysis. In addition, it allows to generate various stress distributions and triaxialities, simply by varying the notch radius. The precracked samples were obtained by fatigue precracking V-notched tensile bars by rotary bending.

The effect of the geometry on the stress-strain curve is shown in Figure 1. The smaller the notch radius, the lower the displacement at fracture and the higher the stress.
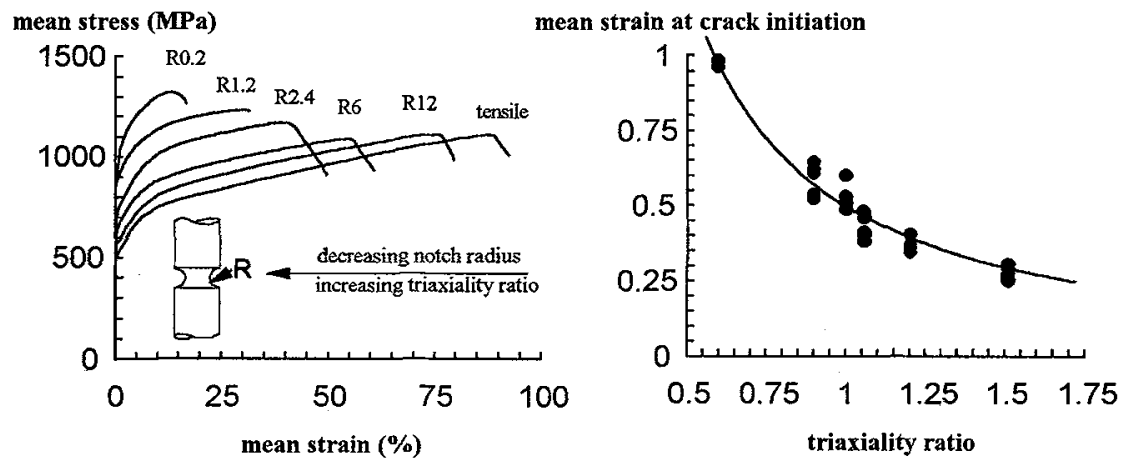

Figure 1. Influence of the notch radius on the stress-strain curve of the 18MND5 material: strain at crack initiation drastically decreases when raising the stress triaxiality ratio.

The tests were performed on a $25 \mathrm{kN}$ servohydraulic INSTRON tensile machine under controlled displacement at a constant crosshead speed of $0.2 \mathrm{~mm} / \mathrm{min}$. The load and the crosshead displacement are continuously recorded. The diameter contraction is also continuously measured with an LVDT. An axial extensometer is used when testing the precracked tensile bars.

\section{FINITE ELEMENT SIMULATION}

Due to the axial symmetry of this notched tensile geometry, only a quarter of the specimen needs to be simulated using two-dimensional isoparametric 8-node elements with reduced Gauss integration. Plasticity is modeled using incremental theory with a von Mises yield surface, associated flow rule and isotropic hardening. The load application is simulated by a vertical displacement of the nodes situated at the upper face. Because of large geometry changes, the updated Lagrangian procedure is used to account for large strains and displacements. The quasi-Newton method (BFGS algorithm) is used to solve the constitutive equations. A typical example of the meshing used for the notched geometry is depicted in Figure 2. 

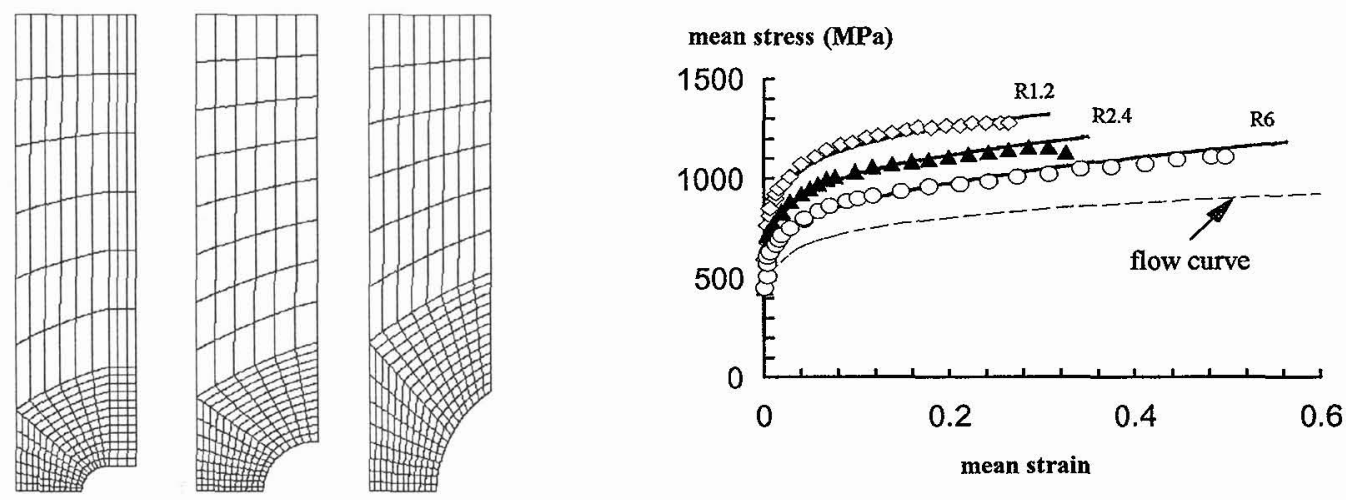

Figure 2. Typical meshing for the notched tensile specimens (notch radius $\mathrm{R}=1.2,2.4$ and $6 \mathrm{~mm}$ ). The size of the element at the centre is $\approx 0.25 \times 0.25 \mathrm{~mm}^{2}$. Good agreement between finite element and experimental data (solid line for finite element simulation and symbols for experimental) is found. The flow curve used for the finite element simulation is indicated.

Comparison between experimental data for ductile behaviour and finite element predictions shows an overall good agreement (Figure 2). The mean strain and mean stress are calculated using the load and reduction of area. When approaching the crack initiation region, the finite element solution increases monotonically while the experimental curve saturates as a result of the onset of void coalescence and subsequent crack initiation: the agreement is still satisfactory.

The precracked notched tensile bar is also simulated in similar conditions. However, an initial crack tip radius of $10 \mu \mathrm{m}$ and $20 \mu \mathrm{m}$ respectively was assumed for $18 \mathrm{MND} 5$ and $\mathrm{A} 508 \mathrm{Cl} .3$ material to account for blunting. A typical mesh is given in Figure 3 together with a comparison between the experimental data and the finite element prediction.
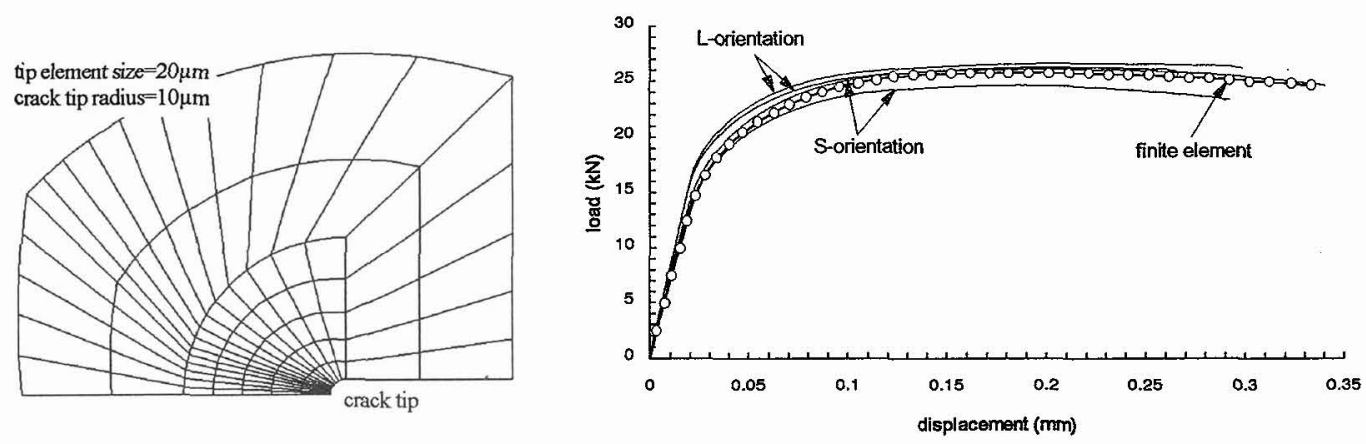

Figure 3. Meshing for the crack tip of the precracked tensile specimen. To account for blunting, the crack tip is modeled with a finite radius of $10 \mu \mathrm{m}$. The radial element size is taken twice the initial crack tip radius. Comparison of the loaddisplacement curve for the 18MND5 steel shows good agreement between finite element and experimental data (solid lines for experimental data and symbol for the finite element simulation).

\section{RESULTS AND DISCUSSION}

Knowing the stress-strain history from the finite element results, the evolution of damage can be easily calculated and the critical value of damage at crack initiation can be derived. In order to evaluate the validity of the proposed models, the influence of geometry (triaxiality ratio), size and orientation were investigated. 


\subsection{Geometry effect}

Within the experimental scatter and the one associated to material variability, the critical damage work corresponding to crack initiation of the $18 \mathrm{MND} 5$ in the S-orientation is relatively geometry independent (Figure 4-a). On the other hand, the critical void growth rate model displays a clear decrease with increasing triaxiality ratio (Figure 4-b). This geometry dependence cannot be associated to the fact that the nucleation phase was neglected because the damage evolution in the range of the nucleation phase is too small to compensate for the observed discrepancies.



a)

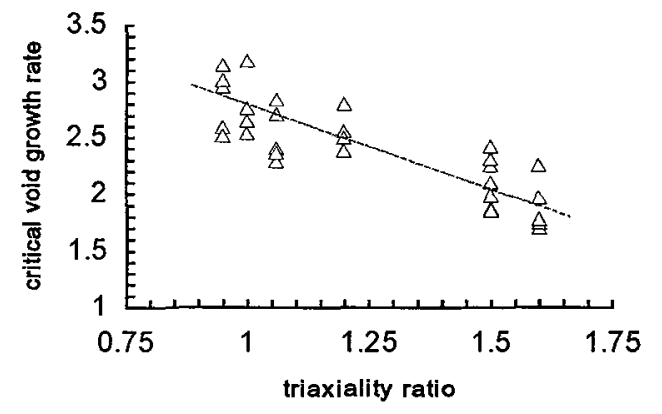

b)

Figure 4. Critical damage versus geometry (triaxiality ratio) for 18MND5 S-orientation: within the experimental scatter, the critical damage work is geometry independent while the critical void growth decreases with increasing triaxiality ratio.

\subsection{Size effect}

Three notched tensile geometries were selected to investigate the size effect: the diameter at the minimum section is $D=10 \mathrm{~mm}$ (6 samples), $6 \mathrm{~mm}$ ( 27 samples) and $3.6 \mathrm{~mm}$ ( 6 samples). The notch configurations were chosen in order to cover a triaxiality range of 0.9 to 1.5 . It is important to keep the centre mesh size identical for the three specimen sizes. The results shown in Figure 5 do not reveal any obvious size influence on the critical damage values $W_{d c}$ of the damage work. Similarly, the critical void growth rate $\left(R R_{0}\right)_{c}$ is size independent.

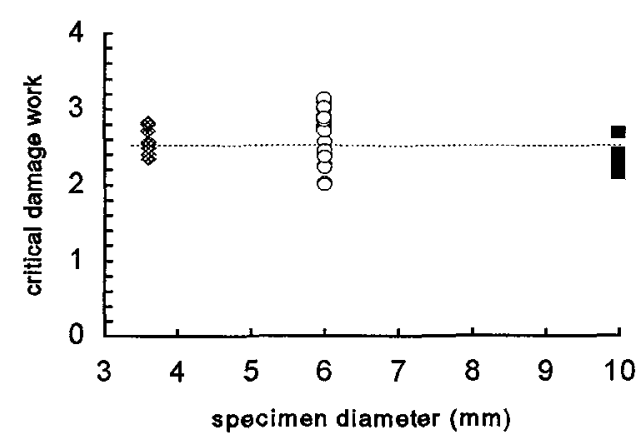

Figure 5. Specimen size does not affect the critical damage work at crack initiation significantly.

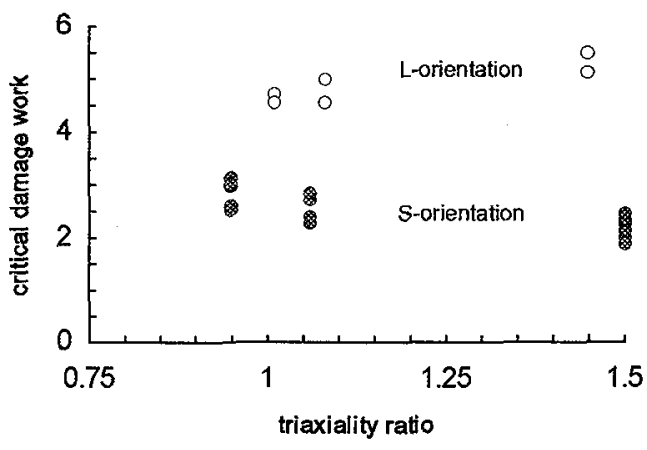

Figure 6. The L-orientation exhibits much higher critical damage work and critical void growth rate than the S-orientation. 


\subsection{Specimen orientation effect}

The effect of specimen orientation can easily be seen from the tensile tests: within experimental uncertainties the yield stress, the ultimate stress and the uniform elongation are relatively identical while the reduction of area and therefore the fracture strain can differ significantly.

This material anisotropy is primarily due to the shape and orientation of the second phase particles present in the material [12]. Wilson [12-14] and Spitzig [15-17] have extensively investigated the influence of inclusion orientation on the mechanical properties of steels. They show that mechanical properties (tensile, Charpy impact and ductile fracture toughness) can drastically change with the content of second phase particles. On the other hand, Becker et al. [18] investigated the effect of void shape on void growth and ductility using finite element calculations. Consistent with the experimental data, they found that the rate of growth was primarily governed by the void dimension normal to the tensile direction. The results obtained on the 18MND5 steel are presented on Figure 6 which indicates that the longitudinal direction leads to higher ductility.

\subsection{Highly constrained geometries}

In the submentioned tests, crack initiation occurs when the critical damage value is reached. In other words, a single parameter allows to define the crack resistance. In fact, a second parameter, masked in these geometries, is required before initiating a crack. Indeed, as suggested by Rice and Johnson [19] for crack tip situations, a distance - called characteristic or critical distance - over which the damage should reach its critical value is required to initiate the crack. Therefore, some tests were performed on V-notched specimens ( $V$-shape notch of radius $\mathrm{R}=0.2 \mathrm{~mm}$ ). In this case, as illustrated in Figure 7, the crack initiates at the notch and propagates towards the centre while for others geometries $(R=0.8$ to $6 \mathrm{~mm}$ ) the crack initiates at the centre and propagates towards the free surface. The damage distribution in the notched samples is so flat that the critical damage is immediately reached over a large distance and consequently, it is very difficult to confidently estimate the characteristic distance. This also results in the sudden load drop experimentally observed after crack initiation. In the Vnotched samples, the onset of crack initiation is more difficult to detect in comparison to other geometries, because there is no sudden load drop at crack initiation. Therefore, the crack initiation onset is estimated by monitoring the change rate of reduction of area with increasing deformation. This change rate is relatively constant until crack initiation accelerates the deformation rate, as confirmed by interrupted tests.

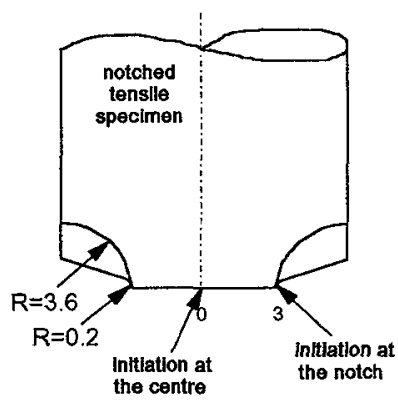

a)

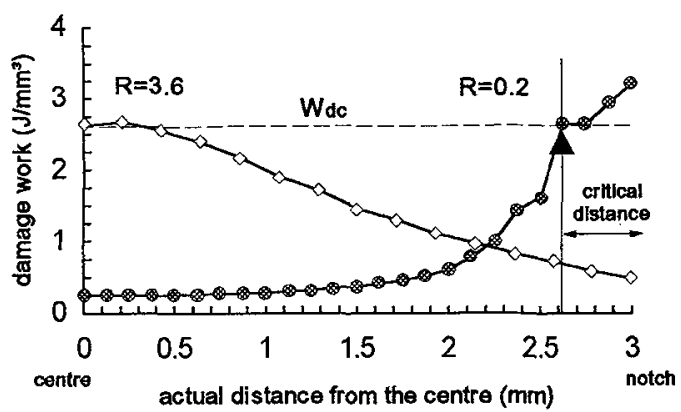

b)

Figure 7. Influence of notch radius over the damage distribution: while critical damage is reached over a relatively large distance at the centre of the notched sample, the distribution becomes steep when the notch radius decreases, showing that the critical damage should be exceeded over a critical distance before a crack can initiate.

This V-notched geometry is very attractive as it will allow the determination of the characteristic distance that can be used for precracked specimens. Mudry [5] has considered a similar procedure to determine the mesh size to be used ahead of a crack. 
The V-notched geometry demonstrates also the competition character between stress triaxiality and plastic deformation. The finite element simulation of this geometry $(R=0.2 \mathrm{~mm})$ allows to determine the evolution of the stress-strain distributions. Figures 8-a and 8-b show, respectively, the evolution of the triaxiality ratio distribution and the plastic strain distribution at the minimum cross section of the V-notched geometry for different deformation levels. The application of the proposed damage models leads to Figure 9 which indicates clearly that the crack will initiate at the notch and propagate towards the centre. This is confirmed by metallographic observation of a cross-section obtained by interrupting a test at the expected crack initiation point [11]. Figure 9 allows to determine the characteristic distance, over which the critical damage must be reached for crack initiation. Indeed, this figure shows that knowing the critical strain at crack initiation ( mean strain $=18.4 \%$ in the present case) and the critical damage determined on other notched geometries (horizontal line at $W_{d c}=2.6 \mathrm{~J} / \mathrm{mm}^{3}$ or $\left.\left(R / R_{0}\right)_{c}=2.5\right)$, their intersection allows to derive the characteristic distance $\left(l_{c} \approx 0.4 \mathrm{~mm}\right.$ on the $\mathrm{x}$-axis $)$. This distance can be interpreted as the process zone size over which the microvoid coalescence process takes place.

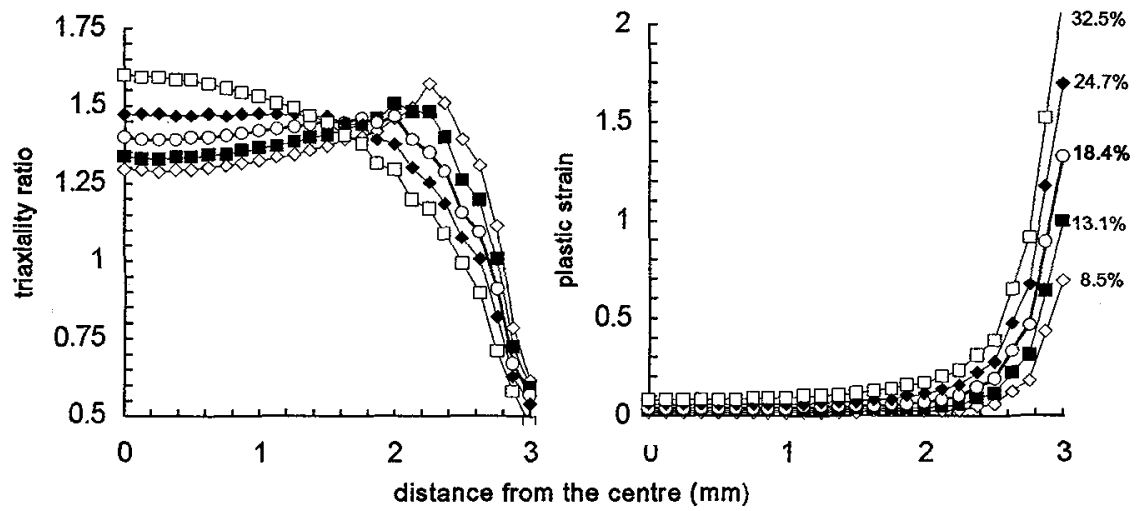

Figure 8. Triaxiality ratio and plastic strain distributions at the minimum cross-section of a notched specimen $(R=0.2 \mathrm{~mm})$ with increasing loading levels (mean strain of 8.5 to $32.5 \%$; crack initiation occurs at a mean strain equal to $18.4 \%$ ).

Another interesting geometry largely used in fracture mechanics evaluations is the precracked sample. A few tensile bars of $10 \mathrm{~mm}$ diameter were precracked to a crack-length to specimen-radius ratio of 0.5 and tested in tension at $20^{\circ} \mathrm{C}$. The load and displacement (measured with an extensometer of $13 \mathrm{~mm}$ initial gauge length) were continuously measured. For each material condition, the tests are interrupted at maximum load and at $5 \%$ load drop. The specimens are then broken in liquid nitrogen. Examination of the fracture surfaces by scanning electron microscopy revealed that ductile crack initiation occurs just after reaching maximum load. Finite element calculations allowed to determine the J-integral by using the energy domain integral method [20]. By applying the same procedure as for the V-notched samples, it is possible to represent similar damage distributions for various applied loads. 


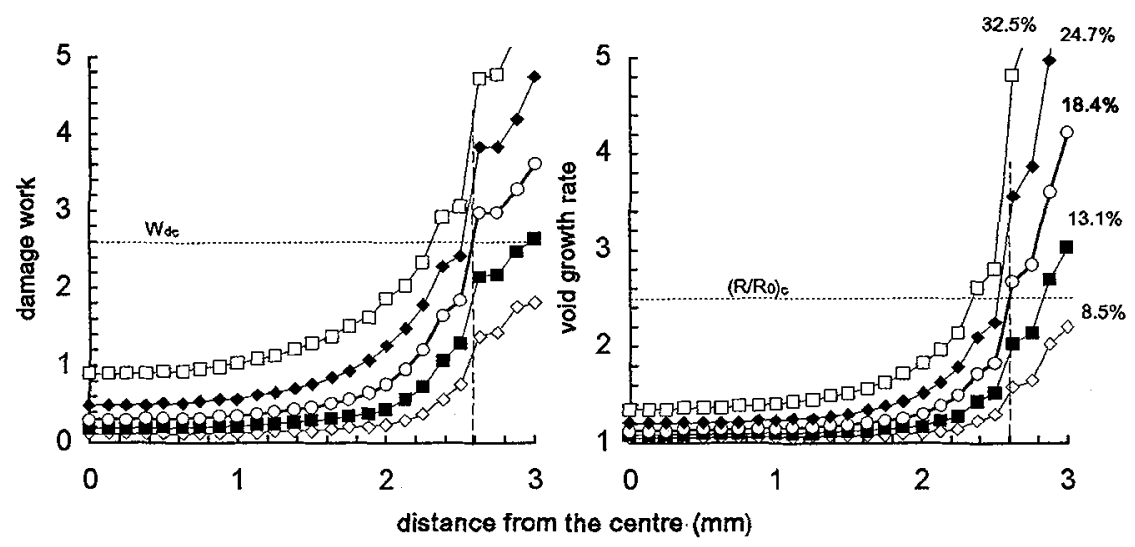

Figure 9. Damage work and void growth rate distributions at the minimum cross-section of a V-notched specimen $(R=0.2 \mathrm{~mm})$ with increasing loading levels: a characteristic distance of $l_{c} \approx 0.4 \mathrm{~mm}$ can be derived.



Figure 10. Damage work and void growth rate distributions at the minimum cross section of precracked tensile bar: the intersection of the critical $J_{c}$ value with the critical damage level allows to derive the critical distance $l_{c}(\approx 0.4 \mathrm{~mm})$.

Figure 10 is obtained by plotting the damage distribution ahead of the crack tip using the finite element results at various J loading levels. This figure shows that in the case of $18 \mathrm{MND} 5$ steel in the S-orientation, the critical distances derived from both precracked and V-notched samples are very similar $\left(l_{c} \approx 0.4 \mathrm{~mm}\right)$. Table 3 reports the various parameters derived from the evaluation of the investigated materials. A critical distance of $\approx 0.4 \mathrm{~mm}$ is derived from the V-notched geometry irrespective of the material. On the other hand, the critical distances derived from the cracked geometry depend on the material and slightly on the micromechanical model that is used. Comparing the two geometries, i.e. the cracked versus the V-notched geometry, it appears that the latter is not really appropriate to accurately derive the critical distance. This is illustrated on Figure 11 which shows that the damage distribution in the $\mathrm{V}$-notched geometry is not steep enough as compared to the crack, consequently increasing the uncertainty to determine the critical distance.

Also reported in Table 3 are the predicted $\mathrm{J}_{c}$ values derived from the various notched geometries. These values are obtained by intersecting the critical damage value (derived from the notched tensile specimens) with the critical distance (derived from the V-notched geometry) on the damage distribution diagrammes obtained from 
the finite element simulation of the precracked tensile bar. Reasonable agreement is obtained despites the following sources of uncertainty:

1. the scatter associated to the material variability;

2. the steep distribution of the damage parameters;

3. the detection of the onset of crack initiation.

The critical distances obtained in this work are reasonable. For comparison, Table 4 shows critical distances taken from literature [21-25] that vary from $0.05 \mathrm{~mm}$ to $0.4 \mathrm{~mm}$ for various materials.

\begin{tabular}{|c|c|c|c|c|c|c|c|c|}
\hline material & orient. & \multicolumn{3}{|c|}{ Precracked Tensile Bar } & \multicolumn{2}{c|}{$\begin{array}{c}\text { V-notched bar } \\
(\mathrm{R}=0.2 \mathrm{~mm})\end{array}$} & \multicolumn{2}{c|}{ Predicted $J_{\mathrm{c}}$} \\
\hline & & $\begin{array}{c}\mathrm{J}_{\mathrm{c}} \\
\left(\mathrm{kJ} / \mathrm{m}^{2}\right)\end{array}$ & $\begin{array}{c}\mathrm{l}_{\mathrm{c}}\left[\mathrm{W}_{\mathrm{dc}}\right] \\
(\mathrm{mm})\end{array}$ & $\begin{array}{c}\mathrm{l}_{\mathrm{c}}\left[\left(\mathrm{R} / \mathrm{R}_{0}\right)_{\mathrm{c}}\right] \\
(\mathrm{mm})\end{array}$ & $\begin{array}{c}\varepsilon_{\mathrm{c}} \\
(\%)\end{array}$ & $\begin{array}{c}\mathrm{l}_{\mathrm{c}} \\
(\mathrm{mm})\end{array}$ & $\begin{array}{c}\text { from } \mathrm{W}_{\mathrm{cc}} \\
\left(\mathrm{kJ} / \mathrm{m}^{2}\right)\end{array}$ & $\begin{array}{c}\text { from }\left(\mathrm{R} / \mathrm{R}_{0}\right)_{\mathrm{c}} \\
\left(\mathrm{kJ} / \mathrm{m}^{2}\right)\end{array}$ \\
\hline \multirow{2}{*}{$18 \mathrm{MND5}$} & $\mathrm{S}$ & 218 & 0.44 & 0.35 & 18 & $0.38-0.42$ & $195-213$ & $227-250$ \\
\cline { 2 - 9 } & $\mathrm{L}$ & 250 & 0.29 & 0.24 & 35 & $0.30-0.40$ & $259-350$ & $310-350$ \\
\hline A508 Cl.3 & $\mathrm{T}$ & 295 & 0.51 & 0.46 & 30 & $0.40-0.45$ & $250-265$ & $276-294$ \\
\hline
\end{tabular}

Table 3. Characteristic parameters derived from the application of micromechanical modeling to the $V$-notched and precracked geometries.

\begin{tabular}{|c|c|c|c|c|}
\hline material & yield (MPa) & $\mathrm{J}_{\mathfrak{c}}\left(\mathrm{kJ} / \mathrm{m}^{2}\right)$ & $\mathrm{l}_{\mathrm{c}}(\mathrm{mm})$ & reference \\
\hline A516 Gr 70 & 335 & 125 & 0.076 & {$[25]$} \\
HY-80 & 631 & 170 & 0.051 & {$[25]$} \\
A508 & 450 & $150-210$ & 0.20 & {$[22-23]$} \\
SA533B Cl.1 & 481 & 262 & $0.30-0.35$ & {$[21]$} \\
SA302B & 465 & 77 & $0.10-0.15$ & {$[21]$} \\
StE 460 & 460 & & 0.40 & {$[24]$} \\
\hline
\end{tabular}

Table 4. Characteristic distances for various materials.

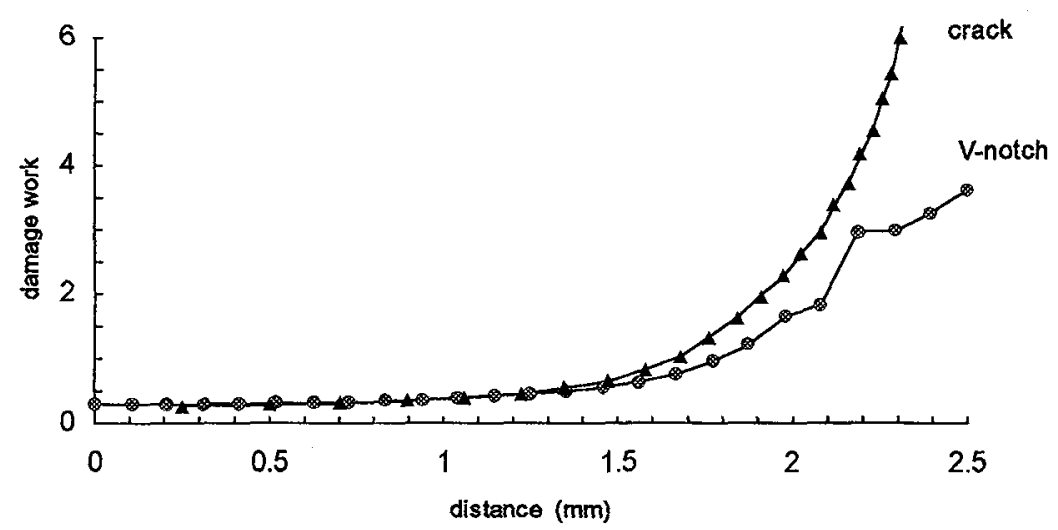

Figure 11. Damage distribution ahead of a crack is much more steep than ahead of a V-notch allowing a more accurate derivation of the critical distance. At the region of interest, the damage distribution is relatively flat thereby increasing the uncertainty on the determination of the critical distance.

\section{CONCLUSIONS}

Two micromechanical damage models were applied to two reactor pressure vessel steels: the void growth model and the damage work model. Both models account for the deformation history of the material. These two 
criteria were applied to tensile data obtained on various notched tensile specimens. The critical damage at crack initiation is found to be geometry and size independent although a slight decrease of the critical void growth rate is noticed when the triaxiality ratio is increased. For the V-notched samples and precracked bars, an additional parameter is introduced corresponding to a critical distance over which the criterion should be reached before crack initiation. The critical distances were derived by analyzing the damage distribution in the specimen at the deformation level corresponding to crack initiation. The results showed that the critical distance derived from the $\mathrm{V}$-notched geometry is quite similar $(\approx 0.4 \mathrm{~mm})$ for both materials and independent of the micromechanical model used. On the other hand, the critical distance derived from the precracked geometry is material dependent. Furthermore, the void growth model results in slightly lower critical distance than the damage work model. The comparison of the damage distribution in both geometries showed that the $\mathrm{V}$-notched geometry with $\mathrm{R}=0.2 \mathrm{~mm}$ is not suitable for accurate determination of the critical distance. In addition, the scatter and the difficulty to accurately identify the onset of crack initiation increase the uncertainty. Nevertheless, these results are very promising as they show that, the combination of the critical damage, determined on the notched samples, with the characteristic distance derived from the V-notched samples, allows finite element simulation of the precracked geometry to determine the critical $J_{c}$-value of the material. Sharp notches and more accurate identification of crack initiation will reduce the uncertainties. Consequently, two local parameters, i.e. the critical damage and the critical distance allow to characterize ductile fracture initiation.

\section{Ackowledgements}

The authors wish to thank Robert Gerard from Tractebel Energy Engineering for supporting this research. E. van Walle and A. Fabry are gratefully acknowledged for reviewing this paper. This work could not be achieved without the help and technical assistance of J.P. Wannijn, L. Van Houdt, R. Sneyers, R. Mertens, P. de Bakker and $A$. Verstrepen.

\section{References}

[1] Rice J.R. and Tracey D.M., J. Mech. Phys. Solids, Vol. 17, 1969, pp. 201-217.

[2] Beremin F.M., "Experimental and numerical study of the different stages in ductile rupture: application to crack initiation and stable crack growth", Three dimensional constitutive relations and ductile fracture, Ed. S. Nemat Nasser, North Holland Pub., 1981, pp. 185-205.

[3] Hancock J.W. and Mackenzie A.C., J. Mech. Phys. Solids, Vol. 24, 1976, pp. 147-169.

[4] LeRoy G., Embury J.D., Edward G. and Ashby M.F., Acta Metall., Vol. 29, 1981, pp. 1509-1522.

[5] Mudry F., "Etude de la nupture ductile et de la rupture par clivage d'aciers faiblement alliés", PhD thesis, Ecole des Mines de Paris, 1982.

[6] Marini B. Mudry F. and Pineau A., Eng. Frac. Mech., Vol. 22, N6, 1985, pp. 989-996.

[7] Goodwin S.J., Noble F.W. and Eyre B.L., Acta Metall., Vol. 37, No. 5, 1989, pp. 1389-1398.

[8] Huang Y., J. Appl. Mech., Vol. 58, 1991, pp. 1084-1086.

[9] Melander A., Acta Metall., Vol. 28, 1980, pp. 1799-1804.

[10] Poech M.H. and Fischmeister H.F., Eng. Frac. Mech., Vol. 43, 4, 1992, pp. 581-588.

[11] Chaouadi R, "Micromechanically-based damage modeling of ductile fracture initiation in reactor materials", $\mathrm{PhD}$ thesis, KULeuven, February 1996.

[12] Little J.H. and Henderson W.J.M., "Effect of sulphide inclusions on the anisotropy of ductile Charpy shelf energy", in Effect of Second-Phase Particles on the Mechanical Properties of Steel, The Iron and Steel Institute, London, 1971, pp. 182-189.

[13] Wilson A.D., "Comparing the effect of inclusions on ductility, toughness and fatigue properties", Through-Thickness Tension Testing of Steel, ASTM STP 794, R.J. Glodowski, Ed., American Society for Testing and Materials, Philadelphia, 1983, pp. 130-146. 
[14] Wilson A.D., "Influence of inclusions on the fracture properties of A588A steel", Fracture Mechanics: 15th symposium, ASTM STP 833, R.J. Sanford, Ed., American Society for Testing and Materials, Philadelphia, 1984, pp. 412-435.

[15] Spitzig W.A., Metall. Trans. A, Vol. 14A, February 1983, pp. 271-283.

[16] Spitzig W.A., Metall. Trans. A, Vol. 14A, March 1983, pp. 471-484.

[17] Spitzig W.A., Acta Metall., Vol. 33, No 2, 1985, pp. 175-184.

[18] Becker R., Smelser R.E., Richmond O. and Appleby E.J., Metall. Trans. A, Vol. 20A, may 1989, pp. 853-861.

[19] Rice J.R. and Johnson M.A., "The role of large crack tip geometry changes in plane strain fracture", in Inelastic Behaviour of Solids, Kanninen, Adler, Rosenfield and Jaffe, eds, McGraw-Hill Bo. Co., 1970, pp. 641-672.

[20] Scibetta M. "Fracture toughness evaluation of circumferentially-cracked round bars", report BLG-716, SCK•CEN, Mol, Belgium, May 1996.

[21] Ritchie R.O., Server W.L. and Wullaert A.R., Metall. Trans. A, Vol. 10A, 1979, pp. 1557-1570.

[22] Devaux J.C., Mudry F., Pineau A. and Rousselier G., "Experimental and numerical validation of a ductile fracture local criterion based on a simulation of cavity growth", Nonlinear Fracture Mechanics : Volume II - Elastic Plastic Fracture, ASTM STP 995, J.D. Landes, A. Saxena and J.G. Merkle, Eds., American Society for Testing and Materials, Philadelphia, 1989, pp. 7-23.

[23] Mudry F., di Renzo F. and Pineau A., "Numerical comparison of global and local fracture criteria in compact tension and center crack panel specimens", Nonlinear Fracture Mechanics : Volume II - Elastic Plastic Fracture, ASTM STP 995, J.D. Landes, A. Saxena and J.G. Merkle, Eds., American Society for Testing and Materials, Philadelphia, 1989, pp. 24-39.

[24] Fricke S. and Brocks W., "Damage by void growth tensile and bend type specimens", Structural Integrity: Experiments-Models-Applications, K-H. Schwalbe and C. Berger Eds., 10th European Conference on Fracture, ECF10, Berlin, 1994, pp. 473-482.

[25] Panontin L. and Sheppard D., "The Relationship between constraint and ductile fracture initiation as defined by micromechanical analyses, ", Fracture Mechanics: 26th Volume, ASTM STP 1256, W. G.Reuter, J.H. Underwood, and J.C. Newman,Jr., Eds., American Society for Testing and Materials, Philadelphia, 1995. 